\title{
SCAFFOLDING COMPLEX TASKS BY OPEN ONLINE SUBMISSION: EMERGING PATTERNS AND PROFILES
}

\author{
Miky Ronen and Dorothy Langley \\ Holon Academic Institute of Technology, Israel \\ Telephone: ++972-3-5026611 \\ Fax: ++972-3-5026612 \\ Email: ronen@hait.ac.il \\ Email: langley@hait.ac.il
}

\begin{abstract}
Students in higher-education courses are often confronted with complex tasks that require application and integration of newly gained knowledge. Different students require different types and amounts of instructional scaffolding for coping with such challenging tasks. The incorporation of asynchronous online elements into academic courses offers various ways of implementing traditional instructional scaffolding methods, as well as the ability to incorporate new strategies made feasible by this medium.
\end{abstract}

This paper presents and discusses the potential and challenges of using open online submission of assignments via asynchronous networking as a strategy for providing differential scaffolding in the preparation of complex tasks (not as an alternative model for online peer collaboration).

A pilot study, performed with five graduate education courses, showed that open online submission of assignments led to spontaneous, informal peer-evaluation, enabling students to learn from peer examples. The detailed analysis of students' activity and their reflections has revealed four typical learner profiles with respect to open assignment submission, self-evaluation and characteristic benefit from peer work.

\section{KEYWORDS}

Peer examples, open online task submission, scaffolding, asynchronous networking

\section{INTRODUCTION}

Assignments and projects emphasize learning and assess students' performances. Higher education courses have assignments that many students find difficult. Difficulties may stem from the size of the body of knowledge that is covered; from the lack of familiarity with the concepts, methods of reasoning, skills, and the use of language within the studied discipline; or from a mismatch between the task design and the student's preferred style. These difficulties act as barriers to high quality performance and sometimes to performance at any level.

The growing sense of accountability for student learning in institutions of higher education (particularly those delivering online instruction) has promoted an appeal to educational theory, practice and technology to provide perspectives and tools for supporting the instructional effort. 
The incorporation of online elements into instruction affords new ways of providing support by teacher or peers. Online peer support can be seen as an extension of the natural collaboration that has always existed among students in the context of performing tasks for course requirements. Students often consult each other concerning tasks that are due, and sometimes students view peer work prior to submission.

Inside instructional settings where learning is viewed as solitary and individual, teachers do not usually regard peer products as a legitimate learning resource. A different stand is taken by the socio-cultural learning paradigm, which is geared towards collaborative learning, and where assignments are often presented as group efforts.

This paper deals with an instructional approach that can be described as pragmatic constructivism [1]. The courses involve group activities during face-to-face meetings and online collaboration through group discussion boards, but students are also required to prepare individual assignments. As we shall show later, each assignment is worded identically for all participants but requires personalized examples, explanations and reasoning. Within the context of our instructional approach, we will explore the idea of open submission of the prepared assignments via asynchronous networking as a possible strategy for scaffolding preparation of complex tasks. The purpose of this study was to describe and analyze online assignment submission patterns, the ways students use submitted peer-work, and how students' behavior relates to some aspects of their self-concepts.

\section{ONLINE SCAFFOLDING FOR COMPLEX TASKS}

\section{A. Scaffolding Complex Task Performance}

Students in higher education courses, especially at the graduate level, are presented with complex tasks often involving critical thinking and creativity. Such tasks require students to apply their newly gained knowledge of general principles to specific new situations, and to integrate and evaluate knowledge from several domains. It is hardly surprising that many students encounter difficulties in performing such complex tasks. Althauser and Matuga [2] describe some of the sources of difficulty that are likely to impede task performance as: not understanding enough of the course material to make even initial progress; unfamiliarity with the materials used in examples or questions; more demanding skills that are needed to apply the concepts, perhaps because more abstract definitions of the concepts are required. These inherent difficulties may have a detrimental effect on course survival.

Students may seek help from the lecturer, or teaching assistant, or from peers. Some students may become so overwhelmed by the complex task that they may not even know how to approach it or what questions to ask. Where in the past a "swim or sink" attitude may have predominated in some academic institutions, nowadays many instructors realize that learning is inherently difficult, feel accountable for student learning, and are concerned with supporting students' learning efforts. The type of support offered will essentially be framed within some theoretical paradigm of learning and instruction.

One of the paradigm shifts in educational thinking during the past several decades has been to move away from the conception of learning as individual, solitary and fundamentally cognitive, towards a conception of learning as related to social and cultural experiences of the individual that shape her/his knowledge acquisition and application. According to the sociocultural theory, learning is viewed as fundamentally social and derived from authentic engagement with others in a community of practice [3]. This directs us to view participants of a course not merely as a collection of single individuals, solitarily absorbing knowledge from the expert instructor, but rather as a group, interacting, questioning, assisting and 
motivating its members towards common learning goals.

The sociocultural theory of learning is associated with Vygotsky's ideas about learning in a social context [4] and the construct of the Zone of Proximal Development (ZPD) that is used to explain the difference between the level of independent problem solving performance of the untrained individual and the performance level achieved under the instructional guidance (scaffolding) of experts or more capable peers. The goal is to actively engage the learner while providing only the necessary supports for eventual independent implementation of such strategies.

Scaffolded Learning refers to various forms of support or assistance provided to learners that enable them to complete a task or to solve a problem that would not have been possible without such support. Scaffolding can be given through hinting, questioning, prompting, probing, simplifying or other similar learning supports.

Online communication tools have the potential to offer support of complex tasks using multiple resources and responding to characteristic student difficulties. We shall now describe the potential and possible drawbacks of some scaffolding methods that can be used in either face-to-face or remote instruction.

\section{Structuring Tools}

Structuring tools are used to subdivide a complex task into smaller, more manageable, chunks and guide the learner along the execution phases. These tools may include templates, navigation tools, instruction sheets, check lists, and other methods. Such tools are often used to support individual or group inquiry projects and can be provided as printable materials or as specifically designed software (e.g. [5, 6]).

Students may fail to use the tools for lack of shared meaning of terms and procedures; students who diligently follow detailed instructions may lose sight of the whole; thus, the assignment should incorporate planned reflection to counteract the effect of step-by-step task execution. To promote independent performance, it is necessary to design a "fading" process, where support is gradually withdrawn.

\section{Inter-Personal Communication}

Inter-personal communication includes all forms of spoken or written verbal communication during or after lessons. Traditionally, this includes face-to-face questions and answers, and, less frequently, telephone consultations and written correspondence. The communication usually involves just two people, is not shared by other possibly interested parties, and often has no permanent record. Traditional interpersonal communication is restricted in time and space, as it may not be considered acceptable for a student to contact the teacher whenever the student is able to or needs to describe a problem situation.

Online personal support can involve synchronous or asynchronous communication. The communication can be shared by different groups and can carry support by teacher or peers (e.g. email, chat and group discussion boards). Online communication with teacher and peers requires an ability to formulate, in writing, relatively well-formed questions and responses. This may not be sufficient or appropriate for all students. Some may hesitate to ask for fear of advertising their ignorance (especially in open group discussion boards), while others may not even know what to ask during initial learning stages. Using this means of communication may require training and acculturation. 


\section{Frequently Asked Questions (FAQs)}

One means of support especially appropriate for complex tasks and amenable to online communication technologies is that of supplying Frequently Asked Questions by the instructor. This should help students focus on important issues related to the assignment and provide essential guidance that has the potential to help students get started.

\section{Examples}

Three types of examples can be used as a means of scaffolding learning: expert examples, graded previous student work, and current student work used for peer evaluation activities. Expert examples are provided by sources of authority and carry a high level of reliability. The other two sources of examples carry lesser levels of reliability.

\section{a. Expert (Worked) Examples}

One of the traditional methods of scaffolding learning in general, and assignment performance, in particular, is through "expert examples," sometimes referred to as "worked examples." These are instructional devices that provide an expert's problem solution for a learner to study. The example can serve to reduce the cognitive load that burdens the novice when confronting a new problem. The instructional intention of providing an example is not to have the learner memorize it, but rather to model ways of thinking, acting and expressing oneself in problem situations. The instructional potential of expert examples is usually measured by the students' resulting ability to correctly transfer knowledge, skills and strategies from the example to new problem situations.

Expert examples can be provided by instructors during lectures or included in textbooks or other printed or electronic resources. Students can be directed to study specific examples or can be given general instructions about the availability of examples and possibly search facilities (e.g. by keywords). The examples can carry various levels of explanation: explicit (as found in textbooks) or available according to learner request (such as in hypertext media e.g. [7]). Expert examples can be provided prior to independent student performance or following assignment submission and assessment.

Because examples are considered basic instructional tools, considerable research effort has been directed towards finding ways of characterizing them and evaluating their effectiveness, as reviewed by Atkinson, and colleagues [8]. Some of the results relevant to our study are that learning from worked examples has been shown to be more effective than sheer practice of solving problems, especially during the initial stages of acquiring problem solving skills. Research results have shown that transfer is enhanced when there are at least two examples presented for each type of problem taught and when students are provided with both simple and complex examples. Finally, there is evidence that the effectiveness of an example is not only a function of the way it is presented, but also of the mental process the learner undergoes while studying the example. According to Chi and colleagues [9] successful learners from examples seem to use anticipative reasoning and principle-based explanations while they are studying given examples.

Most studies dealing with learning from examples focus on rule-based domains such as science, mathematics, geometry or computer science. In such domains there are definitely right or wrong action steps, and a student self-explaining an example needs to search a well-defined search space to explain the example "line by line." This kind of explaining may be difficult, or impossible, in fuzzy, complex domains. 
Effective learning from examples requires an extraction of problem-solving principles and general tactics rather than memorization of specific steps. Students often use examples as sources of imitation based on surface features, which can lead to incorrect solutions and little learning.

"How do I start?" A teacher demonstrating how to solve a problem in class will often be asked (after the solution steps have been completed): "How did you know what formula to start with?" What is often difficult for students to explain is the approach, strategy, and the selection of a certain opening statement in the worked example.

\section{b. Graded Student Work}

Examples of previously submitted, graded students' work can be used to support performance on similar assignments. This type of example is mainly intended to present ideas of scope, structure, style, and format, rather than provide specific content resources. Students can learn from both high and poor quality work about requirements and acceptable standards. This type of example can be particularly useful for students who have little previous experience with complex tasks. However, an instructor may not be able to supply examples of previous student work (especially for novel assignments) or may avoid supplying such examples to prevent students' tendency to imitate them.

\section{c. Peer Assessment}

Peer assessment is included as a significant learning activity in many higher education courses in a variety of disciplines [10]. Students are required to view assignments prepared by other course participants and evaluate their performance, usually according to preset criteria. This instructional strategy is extremely efficient for high level, complex tasks [11, 12, 13]. During peer evaluation, students learn from both good and poor examples of peer work. Peer evaluation is reported to provide a source of learning for both the assessor and the "assessee." For the assessor, peer assessment is a cognitively demanding activity that could help consolidate, reinforce, and deepen understanding. It is reflexive (the assessor reflects on his own work and knowledge); it involves more time on task. Research has shown that evaluating the work of others may be as effective as getting feedback on one's own work [14].

Conducting a formal peer assessment has its drawbacks and limitations [12]. Formative peer evaluation imposes an additional load on teacher and students and is performed after the task is completed, therefore it cannot be used for scaffolding the preparation stages for each and every task in a course.

\section{B. Task Performance, Thinking Styles and Goal Orientation}

The mental process learners undergo while studying an example or attempting to perform a required task can be directed to a certain extent by providing scaffolding in the form of leading questions, hints, templates, etc. However, in order to explain the difference in the quality of students' performance, we need to consider personal differences among students. We shall briefly refer to differences in two domains: thinking styles and goal orientation.

Sternberg $[15,16]$ refers to thinking styles as preferred ways of mental self-government. Using the "government" metaphor, the author defines thinking styles under five categories: functions, forms, levels, scope, and leanings. For example, the "function" category consists of three thinking styles: The legislative thinking style is manifested by a tendency to create, design, act independently, have little assigned structure; the executive thinking style is manifested by a tendency to follow directions and act according 
to a given structure; the judicial thinking style is manifested by a tendency to evaluate and judge people and things.

The instructional significance of identifying different thinking styles lies in the need for compatibility among teaching methods and accompanying tasks and assessment methods. For instance, projects which require independent design and decisions about scope and process are compatible with the legislative thinking style, while lectures that require a certain conformity and attention to authority will benefit the executive/hierarchical thinking styles.

Educators at all levels of the education system, are able to cite examples of different student types regarding the need to really understand, willingness to put in effort, attitude to teacher feedback, and patterns of submitting assignments. In order to explain the difference in the quality of students' performance, we need to consider what Bereiter and Scardamalia [17] call the students' "intentions,” i.e. the underlying cognitive approach to the purpose of performing the required task. This has also been referred to as "learner goal orientation" [18]:

Learner goal orientation is an individual's disposition towards a level of achievement or target for accomplishment in a given learning situation (p. 245).

There have been various attempts to classify students according to their goal orientation [19]. At one end there are students who focus on concrete, task-specific goals, either task completion per se, as a superficial compliance with school requirements, or with a more "serious" view to mastering a procedure and demonstrating proficiency. At the other end there are students who display knowledge-building goals. This orientation is manifested through the tendency to view learning situations as opportunities to improve and make progress, to go beyond the particular task or learnt algorithm, to relate and integrate different parts of their knowledge.

\section{Open Online Submission of Assignments}

In the traditional academic setting, personal assignments are usually submitted directly to the teacher, in printed form or electronically. During the preparation period, students often seek help from their peers and view one another's work. This behavior is common and legitimate, and, at all events, cannot be prevented. Students, who wish to examine peers' work, may find examples of varying quality offered by close friends or other peers who are willing to share their work. If a student who seeks such support cannot find it in good time, he or she may not be able to perform the task within the permitted period.

The online components now incorporated into many higher education courses enable the instructor to intentionally expose students to current peer work (i.e. during the assignment submission period, before teacher evaluation). This may be particularly appropriate for complex tasks that require searching through a fuzzy, personalized space (books one has read, games one knows, etc.). Such tasks may well be scaffolded by peer examples that direct one's thoughts to concrete examples without giving away the solution. Such exposure may combine some of the potential offered by "learning from examples" and "peer evaluation," without imposing an unnecessary load on teacher and students. The assignments we have in mind are such that outright plagiarism is not an option, because the assignment calls for personal input.

We contend that a certain form of "evaluation" may occur when students view assignments submitted by peers (prior to grading and instructor feedback). The viewing can occur prior to or after the student has done some independent work. The purpose of viewing peer work can be to satisfy curiosity, a need for 
further clarification of the assignment, or a need for cues about a possible approach or wording. Regardless of the circumstance, the viewer needs some reference criteria whether to adopt, adapt or reject what she/he has seen.

The pilot study we shall describe was aimed at examining the characteristics, the potential, and the challenges of using open online submission of assignments as a possible strategy for scaffolding complex tasks.

\section{THE STUDY}

Our study was conducted with five graduate education courses during the academic years 2001-2003. The courses were held on-campus and were accompanied by a course web site organized within the HighLearn management system [20]. Each course included lectures, class activities and discussions, four personal assignments, a final project intended for teams of two students and a formative peer-evaluation activity of the final projects. The instructional approach we adopted can be described as "pragmatic constructivism” [1] allowing students to be active, social and creative learners in various contexts.

A group discussion board was used for peer-peer and teacher-students communication on all issues related to the course. The assignments were worded identically for all students but required each student (or team) to perform their work independently. All assignments were openly submitted in the course web site.

\section{A. Sample Assignments}

The courses forming the background of this study all had a similar structure although they dealt with different subjects. For the demonstration of the quantitative aspects, we shall focus on the details of one course: Educational Games \& Simulations. During this one semester course, the students were given the following assignments. For each assignment we shall describe details of relevant prior instruction and the support provided:

A1: The students were required to read a given reference, extract some guiding principles within a theoretical framework, and use them to "describe, characterize and analyze your most enjoyable activity and your favorite game.”

A2: "Present and define an instructional problem that can be effectively addressed by a card game and suggest a structure for the game.” The principles had been previously discussed in class, and students had analyzed selected examples. Relevant resources and materials were provided in the course web site.

A3: The students were required to read a given reference and use it to "Identify a high quality computerbased educational game, characterize and evaluate it." The principles had been previously discussed in class, and students had analyzed selected examples. A template was provided.

A4: "Write your personal reflections on the activity that was performed during the previous course session.” A list of reflection aspects was provided.

PP: Prepare a proposal for the course final project: "Developing a prototype of an educational game or 
simulation.” A proposal format was provided, as well as examples of high quality student projects from previous semesters.

The assignments were presented online, in the course web site, and were accompanied by relevant resources (templates, reading materials and examples). It is important to note that most of the reading material included in the assignments was in English - which was not the students' native language.

In terms of Sternberg's thinking styles [16], assignment A1 matched the executive style, A3 and A4 matched the judicial style, and A2 and the project proposal (PP) matched the legislative style.

\section{B. Open Online Submission Regime}

Each assignment was presented at the relevant stage of the course and assigned a submission deadline. Students submitted their work as a message accompanied by an attached file in a dedicated area (group discussion board) in the course web site. During this period of grace, the teacher did not grade students" work (though he used some input for corrective teaching), and students could re-submit revised work until the official deadline. Students were neither required nor encouraged to view or comment on peers' assignments (A1-A4). The teacher responded to the online submissions of assignments only after the official deadline. In some cases there was no online response, since the assignments were discussed during the following class meeting.

Later, for the project proposal assignment, students were encouraged (though not required) to read their peers' project proposals (PP) and to help peers with comments and ideas. The project proposals received a prompt, open, teacher response followed by further online communication between student, teacher, and peers until the approval of the proposal. The records show up to seven "rounds" of communication, in a period of six weeks, during which revised versions of the project were submitted and discussed online.

\section{Research Questions}

The instructional purpose of the open submission regime was to provide a large, yet manageable, example space that catered to students' different needs for examples, to enable critical self and peer-evaluation, to encourage effort, and to promote a sense of community. Attaining these goals depended on student response, namely submission patterns. Open online submission means "high visibility" — viewing and being viewed by peers. Early submission may show confidence, industriousness, and a basic willingness to share. Late submission may show a lack of confidence or understanding, resulting in a need to view many examples, perfectionism, procrastination, or a certain selfishness and lack of sense of community. Clearly, intrinsic and extrinsic factors, such as assignment difficulty and conflicting commitments, can intervene and affect submission patterns.

The main issues that we have attempted to address in this study are:

- What submission patterns emerge with respect to different students and different assignments?

- To what extent do students regard current peer work (prior to grading by teacher) as a learning resource, and to what extent do they make use of this resource?

- What are the instructional implications of the social nature of open submission of assignments?

As our statement of purpose shows, we are not suggesting a model for online peer collaboration, nor dealing with peer online responses to the postings. Our interest lies in identifying patterns of behavior in 
the open submission setting. Specifically, we wish to shed light on how peer postings are used by students as a possible strategy for scaffolding the individual preparation of complex tasks.

\section{Data Sources}

The study was based on the analysis of the data extracted from the actual online activity and on students' reflections on aspects that were not evident in the course web site. At the end of the courses students filled in a three-part questionnaire:

- Students' self-evaluation of their own overall performance in the course.

- A set of items related to the online open submission of assignments (Appendix).

- An open essay: "Imagine you are presented with a task similar to those you have performed in this course that would be openly submitted in the course web site. Describe and explain your most probable behavior."

In two of the courses, students also reflected on their behavior after the submission of each task and a sample of students was interviewed personally.

\section{RESULTS AND ANALYSIS}

Our study was conducted with five graduate education courses, each dealing with different topics, but very similar with respect to instructional approach and course management. We describe general trends and qualitative results for all the courses and demonstrate the quantitative aspects using the data and contents from one sample course (Educational Games \& Simulations, attended by 17 students). The results are discussed under three main themes: assignment submission patterns, profiles of students' use of peer work, and implications of the social nature of open assignment submission.

\section{A. Assignment Submission Patterns}

The course web site records the actual time (to the minute) each submission was made. Figure 1 shows the submission data for assignment A4 in our sample course. The assignment time (AT) starts when the assignment is posted in the course web site (To) and extends until the official deadline. The submission period (SP) starts when the first assignment is submitted and ends at the official deadline. Figure 1 shows that different students submitted their work at different points during the SP and beyond it. The median submission (MS) indicates the time interval from the submission by half the students until the official deadline. 


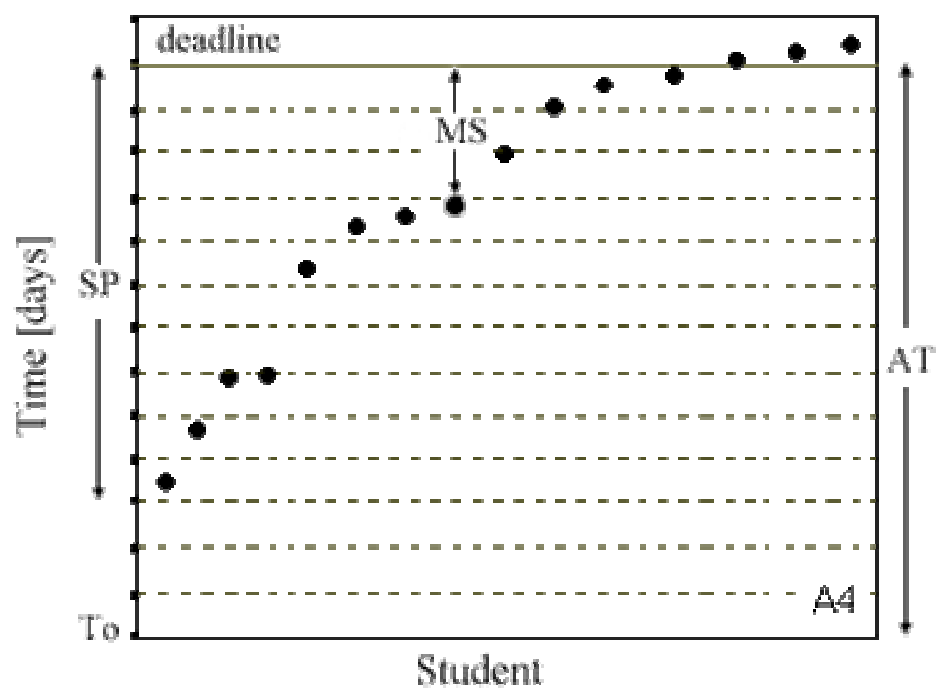

Figure 1: Submission times for a sample assignment (A4)

Table 1 shows the submission data for all the assignments in the sample course. The submission periods (SP) varied between three and ten days, and the time from median submission to deadline (MS) varied between one and three days. This means that half of the tasks in the course were submitted one to three days before deadline and could serve as resources for others.

Table 1: Submission data for the sample course

\begin{tabular}{|l|c|c|c|c|c|}
\multicolumn{1}{c|}{} & $\mathrm{A1}$ & $\mathrm{A} 2$ & $\mathrm{~A} 3$ & $\mathrm{A4}$ & $\mathrm{PP}$ \\
\hline AT [days] & 7 & 7 & 14 & 14 & 21 \\
\hline SP [days] & 3 & 4 & 7 & 10 & 4 \\
\hline MS [days] & 1.5 & 1.5 & 1 & 3 & 2 \\
\hline SP/AT & 0.43 & 0.57 & 0.5 & 0.7 & 0.2 \\
\hline
\end{tabular}

\section{Submission Index}

The time allotted to the assignments in this course (AT) varied between one to three weeks, and the submission period varied between three and ten days. In order to be able to represent, analyze and compare students' behavior between tasks we have defined a normalized Submission Index:

$\mathrm{SI}=(\mathrm{Ti}-\mathrm{To}) / \mathrm{AT}$, where $\mathrm{Ti}$ is the actual submission time; To is the presentation time of the assignment; and $\mathrm{AT}$ is the assignment time, from presentation to deadline. The Submission Index (SI) value represents the order and the relative time of a student's submission for a specific assignment. SI values for submission within deadline may vary between 0 to 1 and SI $>1$ represents late (post-deadline) submissions. The mean SI values for all assignments in the sample course are shown in Figure 2. 


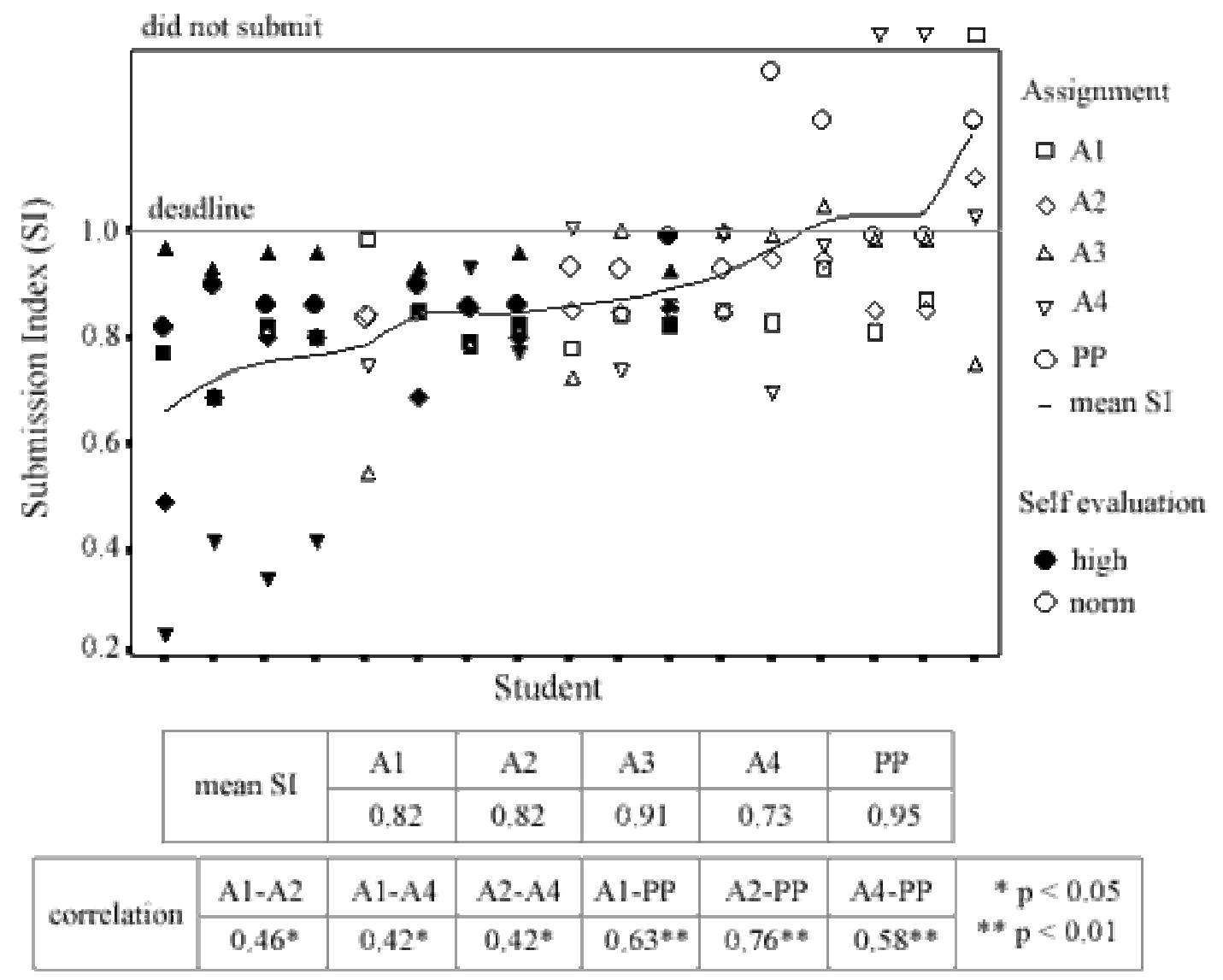

Figure 2: All open submissions in the sample course by students' mean SI.

\section{Submission Patterns for Different Assignments}

The assignments included in each course differed in various aspects, such as the amount and complexity of the theoretical background, the need to search for additional resources, and the compatibility between the assignments and the students' thinking styles. It is reasonable to predict that these differences will affect submission patterns. Using a content analysis as one basis for comparison between submission patterns for different assignments, the findings suggest that submission patterns are related to the level of assignment difficulty, with higher mean submission indices for the more demanding tasks.

Figure 2 shows the variation of the mean submission index related to the assignments for the sample course. Assignment A4 that had the lowest mean SI, (meaning that submissions were relatively early) was the only assignment that did not require additional reading or searching for external resources. The project proposal (PP) had the highest SI (latest relative submission), being the most difficult and demanding assignment.

Assignment difficulty also accounted for a variation in personal submission patterns. A significant correlation was found between the SI values of four of the five submissions in our sample course (Figure 2). This indicates that student submission patterns are determined, at least partially, by personal traits. The exception was assignment A3. The first and crucial part of this assignment was to identify an excellent example from the wealth of existing materials. Good examples are quite scarce, and the more critical one is, and the more aware of the meaning of the evaluation criteria, the more difficult it is to find such an 
example. This may account for later submission by the more discerning students.

Regarding the compatibility of assignments with different thinking styles [16], there does not seem to be a significant relation to submission patterns. Submission patterns for A1 (executive style) and A2 (legislative style) are similar and significantly correlated, while assignments A3 and A4 both matched the judicial style and their submission patterns were very different (attributed to the variation in their level of difficulty).

\section{B. Profiles of Students' Use of Peer Work}

In this section, we shall combine data from students' submission patterns and data from students' written reflections and interviews. In the reflective questionnaire administered at the end of the course, students were asked to evaluate their overall performance as "above average," "average," or "below average." Students classified themselves only in the two first categories, (referred to as "high" / "norm"). Students' self-evaluation matched the teacher's evaluation in all but one case. Students' self-evaluation seemed to play a major role in predicting their assignment submission behavior. The average SI was significantly correlated with the students' self-evaluation (in our sample course $\mathrm{R}=0.72, \mathrm{p}<0.001$ ).

Although students were neither required nor encouraged to do so, they all reported having examined peer work at one stage or another. Students' written reflections and interviews revealed that the open submission of assignments often led to "spontaneous peer evaluation." The following summary shows the general trends for all five courses with percentages given in parentheses for the sample course. Most students (76\%) reported that they had examined submitted peer work before completing their own assignment. Twenty-four percent described instances of entering the course site intending to submit their assignment. Then, after examining submitted peers work, they decided to delay submission in order to improve their product. Quite a few students described situations of completing their assignment but delaying submission in order to be able to examine additional peer examples. Most students (80\%) reported having examined peer work after submitting their own (40\% "always" or "usually"). Some students had revised their work and resubmitted it as a result of examining peers' work (25\%). Nearly half the students reported that peer examples had provided considerable help (42\%). Most students (94\%) reported that the exposure to peer examples had helped them improve their work, and that they had learned from good, as well as from poor examples.

Although all students had examined peers' work at one stage or another, their behavior varied widely on different aspects. For example, only students with high self-evaluation reported that they did not attempt to look at peer submissions before completing their own assignment. An in-depth analysis of students' actual activity and their detailed reflections revealed four profiles of learners' use of peer work (Table 2 and Figures 3 and 4).

Table 2: Learner Profiles in the context of openly submitted peer work.

\begin{tabular}{|l|l|l|l|l|}
\cline { 2 - 5 } \multicolumn{1}{c|}{} & $\begin{array}{c}\text { Independent } \\
\text { Performer }\end{array}$ & $\begin{array}{c}\text { Confident } \\
\text { Performer }\end{array}$ & $\begin{array}{c}\text { Cautious } \\
\text { Performer }\end{array}$ & \multicolumn{1}{c|}{ Survivor } \\
\hline Self -Evaluation & High & High & Norm & Norm \\
\hline $\begin{array}{l}\text { Examine peers' work before completing } \\
\text { own }\end{array}$ & Never & Occasionally & Always & Occasionally \\
\hline Examine peers' work after completing & Occasionally & Usually & Always & Occasionally \\
\hline
\end{tabular}




\begin{tabular}{|l|l|l|l|l|}
\hline own and before submitting & & & & \\
\hline Which and how many? & few selective & few selective & $\begin{array}{l}\text { as many as } \\
\text { possible }\end{array}$ & few - random \\
\hline $\begin{array}{l}\text { May postpone submission in order to } \\
\text { examine more examples }\end{array}$ & No & No & Yes & No \\
\hline Reason for examining peers' work & Curiosity & Compare & $\begin{array}{l}\text { Compare, } \\
\text { understand the } \\
\text { assignment }\end{array}$ & $\begin{array}{l}\text { Understand the } \\
\text { assignment }\end{array}$ \\
\hline $\begin{array}{l}\text { May change own as a result of exposure } \\
\text { to peers' products }\end{array}$ & No & Yes & Yes & Yes \\
\hline Examine peers' work after submitting & Occasionally & Usually & Occasionally & Never \\
\hline $\begin{array}{l}\text { May re-submit after examining more } \\
\text { peers' products }\end{array}$ & No & Yes & No & No \\
\hline Benefit from exposure to peers' work & None-Some & Some & Much & Little - Much \\
\hline Typical Submission & Early & Early & Last minute & $\begin{array}{l}\text { Last minute - } \\
\text { Late }\end{array}$ \\
\hline
\end{tabular}

\section{Independent Performer}

We assigned an independent-performer profile to students who specifically stated that they would never look at current peer work before completing their own (or at least preparing a draft) because they "do not want to be influenced by the ideas of others.” The portion of this profile in our sample courses was about $15 \%$. The students in this group have high self-evaluation, are highly confident and critical thinkers. They submit their assignments as soon as they consider them completed, usually early. The independentperformer profile seems to match the internal/liberal type of learner [15].

Independent-performer type students claimed they were more interested in the teacher's feedback than in their peers' work. Independent performers may examine several selected items before or after submitting their own work, with the main motivation being "curiosity." Looking at peer work would never result in changing their own product after it was submitted. When asked about the benefit of examining peers' work, the typical response for this learner type was: "reading others' works did not help me improve mine." However, they added that they had learned other things about the content and about their peers, such as "different perspectives of the theory," or "how my peers think."

\section{Confident Performer}

The confident-performer profile (representing about $30 \%$ of the students in our sample) is assigned to students with an "above average" self-evaluation. These students stated that they may examine current peer work before preparing their own, with the purpose of selecting the most "reliable sources." Their main motivation is to make sure that their work is as good as, or better than the others'. Once they complete the assignment, they submit it immediately, usually early. Confident performers usually examine current peer work after submitting their own, and their typical characteristic is that they may improve and re-submit their assignments after viewing more examples. Students belonging to this category stated that they may have been affected by the formats and organization of peer products rather than by the contents.

\section{Cautious Performer}

The cautious-performer profile is assigned to students with "average” self-evaluation who tend to submit 
their assignments relatively late or at the last minute, after examining as many peer products as possible prior to preparing and submitting their own. Students in this group admitted that even if they had completed preparing the assignment, they may postpone submission in order to examine more examples. Cautious performers use peer examples to make sure that they have understood the assignment and to compare their own work to others' and try to ensure that their work is as good. This group seems to gain most from peer examples (Figure 4). This profile represents about $30 \%$ of the students of our sample courses.

\section{Survivor}

The survivor profile (representing about $20 \%$ of our sample courses) is assigned to students with an "average" self-evaluation who may examine several random examples prior to preparing their own work. Survivors make sure that they understand the assignment, and they never examine current peer work after submitting their own work. Survivors submit their assignments at the last minute or late, or may not submit at all. Some may use the available peer examples advantageously, while others may not make any attempt to use these resources. The behavior of students in the Survivor group seems to be related to relatively low ability, low motivation, or conflicting commitments. It could also be related to "academic procrastination," known to be associated with poor academic performance, especially in deadlinerestricted courses [21-24].

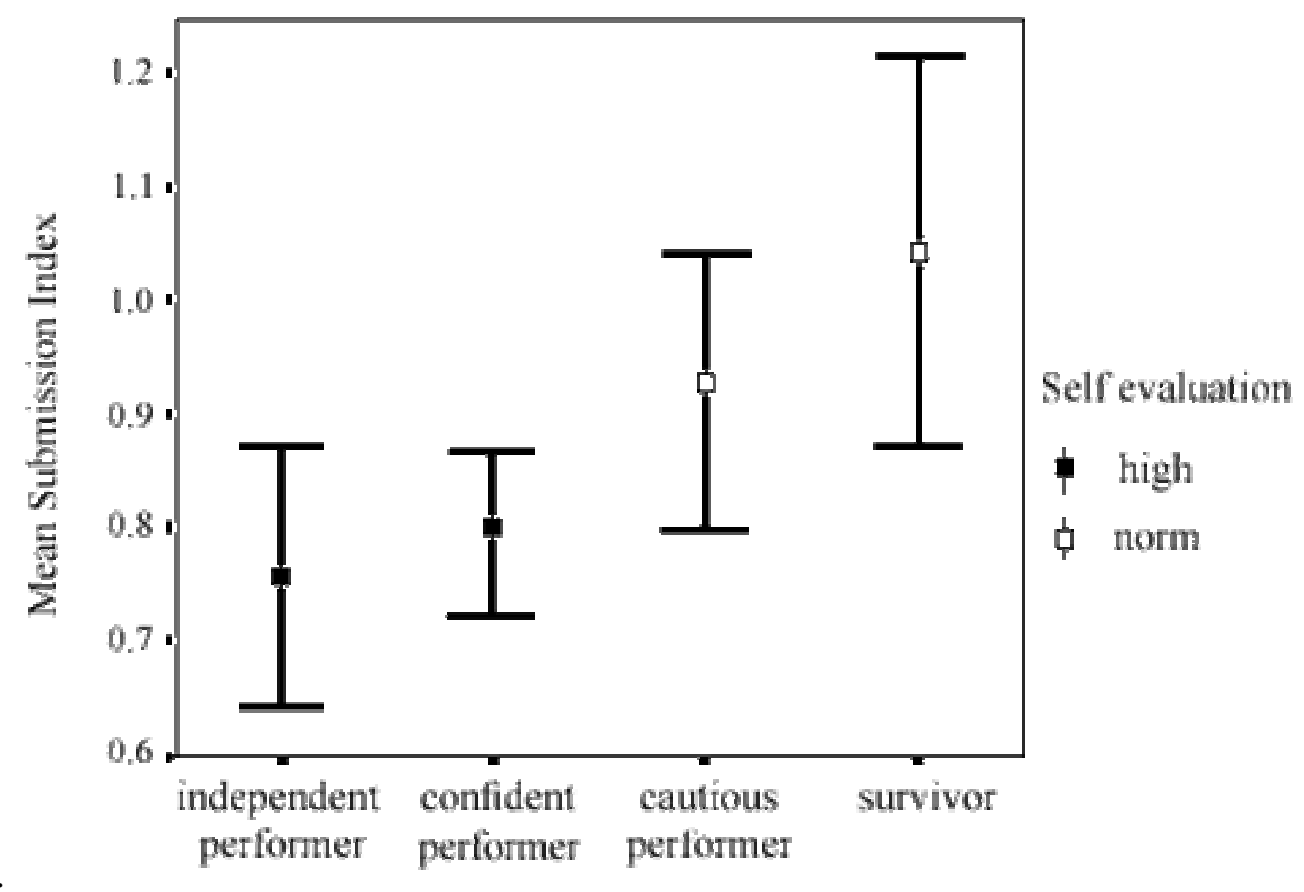

Figure 3: Mean SI for the different profiles. 


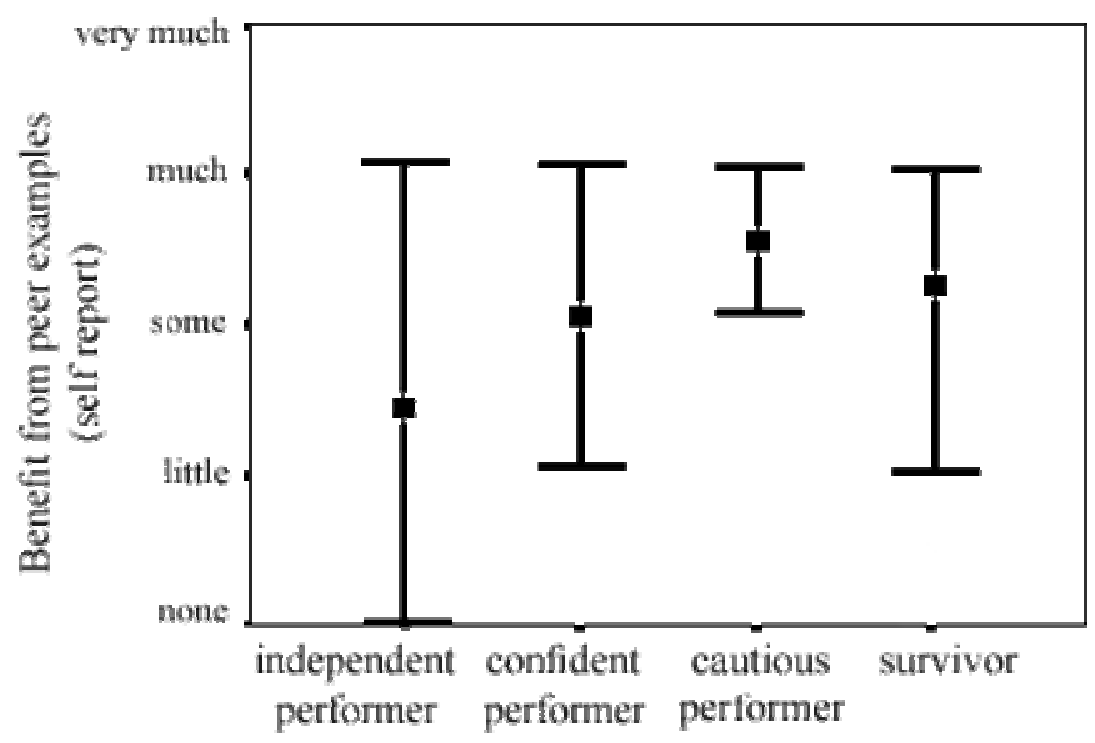

Figure 4: Self-reported benefit from peer examples for the four profiles.

\section{Summary of Student Use of Current Peer Work}

Figure 3 provides data from our sample course and allows us to understand the dynamics of the process with Independent and Confident Performers submitting their work relatively early, thus enabling others to take advantage of these resources. Clearly, task difficulty and type can affect personal submission patterns. This may explain the relatively late submissions of A3 by even confident and independent performers, relative to their usual behavior in all other tasks. Students may also examine peer work after submitting their own assignments, and later resubmit a revised version.

Our findings suggest that the open online assignment submission regime can serve as an effective "personalized scaffolding" method, offering different support to different students (Figure 4). In general, our findings are similar to those reported by Baker and Dillon [25] who concluded that the less confident students had gained more from peer support on the web.

The four profiles we have defined represent different behavior patterns in the context of exposure to submitted peer work and using it for "learning from examples." It seems that the profiles are related to the students' personal characteristics, such as thinking style, goal-orientation, self-confidence, motivation and creativity. Although individual behavior varied sometimes due to personal circumstances (e.g. missing the relevant class meeting), we found that when the experience is repeated (4-5 times in a course), students' behavior seems to be quite consistent, as shown in Figure 2. Furthermore, nine of the students in our sample participated in two courses included in this study (in subsequent semesters) and their typical behavior was similar in both courses.

\section{Implications of the Social Nature of Open Assignment Submission}

The central characteristic of open assignment submission is the high degree of visibility by peers and teachers. Thus, the submission of an assignment is transformed from a private transaction between student and teacher, to a relatively public event within the social context of the course. 
This transformation can have different consequences for students, depending on their beliefs, personality, and aptitude (particularly with respect to written documents in a computer based environment). The teacher has a decisive role to play in creating and fostering a course atmosphere that reduces students' anxiety and promotes participation in the spirit of "intentional learning” [17].

\section{What are the Manifestations of the Social Nature of Open Assignment Submission?}

Students stated that open submission is different from private submission to the teacher. A common reaction was "I was more cautious since I knew that all the others will see it." This type of reaction is well documented in research comparing online written communication with face-to-face discussions [e.g. 26-28].

Another phenomenon can be labeled "not wanting to be the first." Students in all groups reported that they had entered the course web site intending to submit their assignment, but realizing that there were no prior submissions, they decided to postpone their submission to avoid being the first. Self-consciousness about being the first is also evident from the cover messages by those who do "start the ball rolling": "Here is the first task" or "Am I brave or stupid?" This show of courage will often be rewarded by an encouraging or grateful response: "Cheers, I've been trying to start this task but have no clue how to approach it-you have helped me a lot." This is a clear acknowledgement of the social service the contributor has performed by sharing his/her work with the group. This type of behavior was quite typical for the first assignment in each course.

Although the assignments were officially "submitted to the teacher," most of the cover messages were addressed to peers: "I have attached my work-I hope you all enjoy it," while some invited peers to comment. In one of the courses, a student complained that peers had not responded to her submission. The nature of the comments that were made spontaneously by some of the students also indicates a need to observe social protocol and avoid critical comments. The comments were mostly compliments on the good work. In their written reflections, most students reported that they had identified faults and problems in peers' assignments. In such cases they either refrained from all comment, or provided private oral comment and only rarely, submitted online remarks regarding the contents. Corrective technical feedback (e.g. when the attached file was corrupt or incomplete) was also considered inoffensive and helpful.

While most students seemed to adapt quite naturally into the social atmosphere, some students persisted in viewing open submission as a technicality and in fact used the open platform as a means of presenting their work to the teacher and communicating with her, completely ignoring peers. This attitude, reflected in the cover messages, usually faded out as the courses advanced.

There was a notable difference between voluntary participation related to the regular assignments and the teacher-encouraged and rewarded participation in feedback on project proposals (PP). The same three or four students (in each course) responded online to peer-submissions. Most of the students remained passive.

In their written reflections and interviews, students admitted to being pragmatic: "I liked this approach (of open online submission) because my immediate goal was to improve my own product and I could do so without having to comment on the work of others."

For the project proposals, where response was specifically encouraged and rewarded by the teacher, peer comments were more frequent and included valuable queries, remarks and suggestions related to the 
content. In some cases, these comments resulted in lengthy online discussions between peers, helping each other or arguing about issues related to specific projects.

\section{In What Ways can the Open Submission Conflict with Student Held Beliefs and Principles?}

Many students have been educated in a traditional instructional approach that views learning as essentially individual and discourages cooperation between students during task performance. This instructional approach sees the class as a collection of individuals all directing their attention on the teacher, possibly competing for her approval and praise through the attainment of high grades. To this day this is the predominant approach in many formal educational institutions. In higher education, the students may themselves be teachers who practice such an approach and strongly believe that the only "real knowledge” is that which is gained through individual effort.

Students sharing this belief may feel uncomfortable about "peeking" at current peer work. It may seem to them as too easy a way of doing their work or clarifying uncertainties. To students it may seem quite legitimate to implement an idea they find in a book, but they may feel that adopting a colleague's idea is a form of plagiarism. This attitude was reflected in the apologetic phrasing of some of the student's written reflections describing their use of peer's examples: "I viewed some examples and corrected my work twice. Am I a copycat?"

\section{Effects of Open Submission on Students’ Work}

\section{a. Improving Assignment Quality:}

Most students (70\%) stated that they had benefited from good as well as from poor examples. However, some of the students in our sample were specifically seeking "reliable resources," thus regarding the experience as "learning from expert peers." The confident- and cautious-performer types tended to improve their products as a consequence of viewing peer work: "Even if I have already submitted, I still had an option to change and improve my work."

\section{b. Encouraging Reflection and Revision:}

Some students described how examining peers' work gave them ideas relevant to their subject, sometimes in an associative way. Others mentioned adopting format and structure aspects they had liked in peers' work.

\section{c. Possibly Encouraging Uncritical Imitation and "Herd-Like Behavior":}

Benefiting from examples, and especially peer work that has not been graded, depends on having a basic understanding of the ideas and principles involved, along with applying critical thinking. The analysis of students' performance has revealed instances of superficial use and misinterpretation of details adopted from peer work. Peer work might mislead students who lack the ability and skills to evaluate and selectively use the available information. This is especially true for complex tasks with insufficient scaffolding.

An example: In one of the courses (not the sample course described earlier), students were required to analyze a certain instructional approach and to relate it to given principles and theories. The students were asked to represent their analysis in a table format. When the task was presented, students immediately asked for clarifications on "how to present it in a table format?" One of the goals of this task was to 
produce, then to examine, different representations of the complex relations between the theories and their implementation.

Any clarification would require the teacher to provide a specific example of a format, and the teacher feared that all students would imitate the example. Therefore, she intentionally decided not to provide additional scaffolding. The time allotted to this task (AT) was three weeks. The first four assignments submitted were poor and did not comply with task requirements. The first task that met the requirements was submitted after one week. Only one of the additional 11 assignments that were submitted during the remaining two weeks was satisfactory (submitted three days before deadline). All the others were similar to the first poor versions. According to their reports, all but one of these 11 students had read previously submitted peer work. Nevertheless, students could not distinguish the (one or two) good examples from all the rest. Instead of learning from these good examples, students seemed to have "followed the crowd." In their reflections (written immediately after the deadline and before teacher's feedback on this task), students even stated that the task was not difficult.

\section{Issues of Competitiveness, Sharing and Procrastination}

A student reflected on the idea of open submission of assignments and wrote on the back of the questionnaire sheet: "Our sages said that the bible was written for both the learned and the layman. Open submission of assignments allows everybody to take and learn from others whatever they can and feel they need in order to improve their products.” In contrast to the generous spirit expressed by this student, some faculty colleagues have pointed to several problematic aspects that might challenge the educational benefits of an open assignment submission regime.

One of the aspects that might affect students' willingness to share is the level of feeling of being part of a group working toward common goals. Student competitiveness might result in unwillingness to let others "take advantage" of their work, thus encouraging the better students to delay assignment submission until the last minute. This trend would clearly work against the idea of peer work providing scaffolding for those more in need of it.

In our five sample courses, none of the students expressed any objection to openly submitting their assignments, nor was there any evidence of students postponing submission in order to prevent peers from taking advantage of their work. Rather, we found that some students expressed their sense of community by consciously letting others use their examples and by commenting on peers' work. Serving as models for others seemed to be a strong motivating factor for some of the students, especially if no extra effort was required to gain this appreciation.

Nevertheless, these concerns may be justified for many higher education courses, and, therefore, should be addressed explicitly by teacher actions aimed towards fostering a sense of community during the faceto-face meetings and the online activities. The teacher can encourage early submission of assignments either by offering the "early birds" a certain bonus (extrinsic motivation) or by highlighting the prestige related to "being first" and helping others:

"You are not required to submit the assignments before the specified deadline, but please note that assignments that are submitted early may help others, and therefore will be valued by your peers (and also by the teacher). Please keep in mind that peer examples may not be excellent, and you need to apply critical thinking and personal judgment before you decide to adopt and use any part of them." 
Another relevant aspect that was brought up by faculty colleagues was that students might postpone coping with a task while waiting for relevant resources to appear. We need to address the question whether the open assignment submission regime might encourage academic procrastination.

Procrastination is an interactive, dysfunctional, and behavior-avoidance process, characterized by the desire to avoid an activity, the promise to get to it later, and the use of excuse-making to justify the delay and avoid blame. Academic procrastination is regarded as a dispositional trait that can have particularly serious consequences for students, whose lives are characterized by frequent deadlines. Procrastinators frequently use excuses (both legitimate and fraudulent) to justify their behavior and gain more time [29]. "Waiting for resources to appear" cannot be used as a legitimate excuse for late submission, though it may serve procrastinators to rationalize their behavior, especially those who tend to postpone work because they claim "I don't know how to do it" — a claim that is related to skill deficiency [21].

As expected, none of the students in our courses admitted to having postponed working on the tasks while they waited for peer examples to appear. Survivor-type students stated that they had used peer examples mainly to "understand the task" better. Compared with the traditional regime of submitting tasks directly to the teacher, the common "I did not understand how/what to do" excuse had completely disappeared from the repertoire of excuses used by students to justify late or non-submission of assignments. Some of the students in our sample provided common excuses for late submission, the most popular being "I had technical problems with my computer."

Studies on procrastination suggest that this behavior is related to self-regulation and that some of its possible sustaining forces are the characteristics of the course and the instructors [29]. We claim that the nature of the assignments in our courses, the strict submission deadlines, the asynchronous communication channels, the public nature of assignment submission, and the scaffolding it provides may reduce the ease with which the procrastinators can rationalize their late performance.

\section{CONCLUDING REMARKS}

We have described a pilot study exploring the idea of open online submission of assignments as a possible way of utilizing asynchronous learning networking for providing personalized scaffolding for complex tasks. Using current peer work as an additional resource imposes a relatively small load on the students (especially in small groups) and practically none on the teacher. For us, the positive results lie in the sheer response of students to the regime we dictated, in the fact that some students unselfishly posted their work early, that students viewed peer work and were inspired to revise their own and sometimes resubmit it. These results are not to be taken for granted, nor do they stand alone. Rather, these results need to be seen as a result of the entire instructional framework of courses which encourage sharing, participation, and reviewing.

It is important to note that providing access to submitted peer work is not intended to replace other scaffolding methods (templates and worked examples, online teacher and peer support, or formal peer evaluation), nor is it suggested as a model for online peer collaboration. Rather, we suggest using it within a consistent pedagogy, in conjunction with other instructional strategies, only whenever relevant and appropriate.

Open online submission of assignments is not suitable for all subjects and all assignment types. It could only be used for tasks that can be personalized, so that viewing good, as well as poor examples, does not trivialize or compromise the demand that students perform the assignment independently and 
autonomously. Since in many advanced-level academic courses the assignments tend to be personalized, our experience may serve to demonstrate that the suggested approach is effective and easily feasible with the available technology.

Our small-scale study on graduate students has led us to identify and characterize four profiles of student use of current peer work. Further research is necessary in order to validate and refine this characterization and to generalize it to include different groups of students (i.e. undergraduates) and different types of assignments in various subject matter domains.

An additional feature of this pilot study is the small group size. Thus, students were exposed to a relatively limited number of peer examples, which reduced the effort required to read peer work, evaluate it (possibly responding with some comment), reflect on one's own task, and possibly revise it. In larger groups where personal acquaintance with most peers is less likely, the strategy students use to select examples and issues of effectiveness will probably become a critical issue. Further research should explore how students act in large study groups, and how they select and use peer examples.

Open online assignment submission provides the teacher with a window for monitoring assignment submission. It allows teachers to detect possible ambiguities or sources of misunderstanding in the task formulation, or to detect student difficulties in interpreting the task, which may require timely intervention. The teacher's response strategies can have a decisive effect on student behavior. It may be important for the teacher to delay his or her response so that other voices can be heard. In the pilot study, the teacher adopted a non-directive approach for most of the assignments. Further research will enable the testing of different response strategies and their effect on the fruitfulness of the open online assignment submission regime.

The scaffolding provided by peer work depends on different submission patterns of different students. In particular, it relies on the relatively early submission by the more capable students. However, competition and an unwillingness to share can sabotage the strategy. We need to address ways in which the teacher can foster a group spirit and an atmosphere of sharing, and tone down natural competitiveness. We also need to deal with assessment policy decisions. Should early submission be rewarded? Should revision be rewarded? Before widely adopting this strategy (whenever relevant), it is important to understand more about how and what students learn from current peer work, and what are the common pitfalls and problems. Such knowledge is necessary for providing effective guidance to students who are exposed to these resources.

\section{REFERENCES}

1. Perkins, D. The many faces of constructivism. Educational Leadership 57(3): 6-11, 1999.

2. Althauser, R. \& Matuga, J. M. On the pedagogy of electronic instruction. In C. J. Bonk and K. S. King (Eds.), Electronic Collaborators: Learner-centered Technologies for Literacy, Apprenticeship and Discourse. Mahawah, NJ: LEA Associates, 1998.

3. Kahn, T. M. A learning agenda: Putting people first. Palo Alto, CA: Institute for Research on Learning, 1993.

4. Vygotsky, L. S. Mind in Society: The development of higher psychological processes. Cambridge, MA: Harvard University Press, 1978.

5. Shimoda, T. A., White, B. Y. \& Fredriksen, J. R. Student goal orientation in learning inquiry skills with modifiable software advisors, Science Education, 86: 244-263, 2002. 
6. Kolodner, J. L. and Nagel, K. The Design Discussion Area: A Collaboration Learning Tool in Support of Learning from Problem-Solving and Design Activities, Proceedings of CSCL 99. Palo Alto, CA, 300-307, 1999.

7. Brusilovsky, P. WebEx: Learning from examples in a programming course. In W. Fowler and J. Hasebrook (Eds.), Proc. of WebNet'2001, World Conference of the WWW and Internet, Orlando, FL, AACE (2001), 124-129. Available online: http://www2.sos.pitt.edu/ peterb/papers/WevNet01.html.

8. Atkinson, R. K., Derry, S. J., Renkl, A. \& Wortham, D. Learning from examples: Instructional principles from the worked examples research. Review of Educational Research 70: 181-214, 2000.

9. Chi, M. T. H. \& Bassok, M. Learning from examples via self-explanations. In L. B. Resnick (Ed.), Knowing, Learning and Instruction: Essays in honor of Robert Glaser, 251-282. Hillsdale, NJ: Erlbaum, 1989.

10. Topping, K. Peer assessment between students in colleges and universities, Review of Educational Research 68(3): 249-276, 1998.

11. Blumhof, J. \& Stallibrass, C. Peer Assessment. Hatfield, UK: University of Hertfordshire Press, 1994.

12. Zariski, A. Student peer assessment in tertiary education: Promise, perils and practice. In: J. Abbott and L. Willcoxson (Eds.), Teaching and Learning Within and Across Disciplines, 189-200. Proceedings of the 5th Annual Teaching Learning Forum, Murdoch University, February, 1996. Online. Available online: http://cea.curtin.edu.au/tlf/tlf1996/zariski.htm.

13. Althauser, R. \& Darnall, K. Enhancing Critical Reading and Writing through Peer Reviews: An Exploration of Assisted Performance, Teaching Sociology 29(1): 23-35, 2001.

14. Dominick, P. G., Reilly, R. R. \& McGourty, J. The effects of peer feedback on team member behavior. Group and Organization Management 22: 508-520, 1997.

15. Sternberg, R. J. Thinking Styles. Cambridge University Press, New York, 1994.

16. Sternberg, R. J. Allowing for Thinking Styles. Educational Leadership 52(3): 1994. Available online: http://www.ascd.org/readingroom/edlead/9411/sternberg.html.

17. Bereiter, C. \& Scardamalia, M. Intentional learning as a goal of instruction. In L. B. Resnick (Ed.), Knowing, Learning and Instruction: Essays in honor of Robert Glaser, 361-392. Hillsdale, NJ: Erlbaum, 1989.

18. Shimoda, T. A., White, B. W., \& Fredriksen, J. R. Student goal orientation in learning inquiry skills with modifiable software advisors. Science Education 86: 244-263, 2002.

19. Ng, E. \& Bereiter, C. Three levels of goal orientation in learning. In A. Ram and D. B. Leake (Eds.), Goal-driven learning, 355-380. Cambridge, MA: The MIT Press, 1994.

20. HighLearn - Britannica Knowledge Systems. Available online: http://www.britannica-ks.com.

21. Tuckman, B. W. Academic Procrastinators: Their Rationalizations and Web-Course Performance. APA Symposium Paper, Chicago, 2002.

22. Wesley, J. Effects of ability, high school achievement and procrastinatory behavior on college performance. Educational and Psychological Measurement 54: 404-408, 1994.

23. Beck, B. L., Koons, S. R. \& Milgram, D. L. Correlates and consequences of behavioral procrastination: The effects of academic procrastination, self-consciousness, self-esteem, and selfhandicapping. Journal of Social Behavior and Personality 15: 3-13, 2000.

24. Steel, P., Brothen, T. \& Wambach, C. Procrastination and personality, performance and mood. Personality and Individual Differences 30: 95-106, 2001.

25. Baker, J. \& Dillon, G. Peer Support on the Web. Innovations in Education and Teaching International 36(1): 65-70, 1999.

26. Kang, I. The use of computer mediated communication: Electronic Collaboration and Interactivity. In: C. J. Bonk and K. S. King (Eds.), Electronic Collaborators: Learner-centered Technologies for Literacy, Apprenticeship and Discourse. Mahawah, NJ: LEA Associates, 1998.

27. Meyer, K. A. Face-to face versus threaded discussions: the role of the time and higher order thinking. Journal of Asynchronous Learning Networks 7(3): 55-65, 2003. 
28. Sengupta, S. Exchanging ideas with peers in network-based classrooms: An aid or a pain? Language Learning and Technology 5(1): 103-134, 2001.

29. Ferrari, J. R., Keane, S. M., Wolfe, R. N. \& Beck, B. L. The Antecedents and Consequences of Academic Excuse-making. Research in Higher Education 39(2): 199-215, 1998.

\section{APPENDIX: QUESTIONNAIRE ITEMS REGARDING OPEN ONLINE SUBMISSION OF ASSIGNMENTS}

During the course you posted your assignments in the course site openly, so that your work could be viewed by everyone else. This questionnaire will help you reflect upon the experience. Please relate to the following questions and add your comments:

1. Did you view your peers' products before submitting your own work?

If you did,
$\square$ never
occasionally
$\square$ usually
$\square$ always

a. What was the purpose (tick all applicable):

Just out of curiosity

$\square$ To make sure I understood the task

To make sure that my work is as good as the others'

Other:

b. How many and how did you select which products to view:

Few, randomly chosen

Few, selected by

As many as possible

$\square$ Other

2. Did you view your peers' products before completing your own work?

$\square$ never $\quad \square$ occasionally $\quad \square$ usually $\quad \square$ always

Comments:

3. Did you view your peers' products after completing your own work but before submitting it?

Comments:

$\square$ never $\quad \square$ occasionally $\quad \square$ usually $\quad \square$ always

4. Did you ever postponed your submission (after preparing your own work) until you viewed your peers' products? $\quad \square$ no $\square$ yes

Comments:

5. Did you ever access the site intending to post your work, but decided to postpone your submission and improve your work upon viewing your peers' products? $\quad \square$ no $\quad \square$ yes

Comments:

6. Did you ever view your peers' products after submitting your own work?

Comments:

7. Did you ever revise your work and then resubmit it after viewing your peers' products? $\square$ no $\quad \square$ yes Comments:

8. To what extent did you benefit from viewing your peers' products? 
$\square$ none $\quad \square$ little $\quad \square$ to some extent $\quad \square$ much $\quad \square$ very much

Provide examples and explain in what ways:

9. Viewing your peers' products was mainly useful for discovering:

$$
\square \text { what to do } \square \text { what not to do } \quad \square \text { both }
$$

Comments:

\section{ABOUT THE AUTHORS}

Prof. Miky Ronen is the chair of the Instructional Systems Technologies Department at the Holon Academic Institute of Technology and a fellow teaching professor at the department of Education at Haifa University. Her research focuses on the instructional design of interactive learning environments and on the incorporation of technology in the teaching and learning process. She has designed and taught numerous online graduate, undergraduate and teacher training courses and faculty training programs.

Email: ronen@hait.ac.il

Dr. Dorothy Langley is a faculty member in the Instructional Systems Technologies Department at the Holon Academic Institute of Technology and a member of the Physics group at the Department of Science Teaching at the Weizmann Institute of Science. Her research focuses on student learning in information-technology based environments with a special interest in inquiry activities, teacher education and science teaching. She has designed and taught numerous in-service courses for science teachers on the use of technology and its incorporation into teaching and learning.

Email: langley@hait.ac.il 

